\title{
Sinopse taxonômica da família Lauraceae no Estado do Rio de Janeiro, Brasil
}

\author{
Alexandre Quinet ${ }^{1}$
}

Recebido em 13/07/2004. Aceito em 07/01/2005

\begin{abstract}
RESUMO - (Sinopse taxonômica da família Lauraceae no Estado do Rio de Janeiro, Brasil). O presente trabalho consiste de uma sinopse taxonômica dos gêneros da família Lauraceae no Estado do Rio de Janeiro, Brasil. Constatou-se a ocorrência de cerca de 109 espécies distribuídas em 16 gêneros: Aniba Aubl., Aiouea Aubl., Beilschmiedia Nees, Cassytha L., Cinnamomum Schaeff., Cryptocarya R. Br., Endlicheria Nees, Licaria Aubl., Mezilaurus Kuntze ex Taub., Nectandra Rol. ex Rottb., Ocotea Aubl., Persea Mill., Phyllostemonodaphne Kosterm., Pleurothyrium Nees, Rhodostemonodaphne Rohwer \& Kubitzki e Urbanodendron Mez. Foi elaborada uma chave para identificação dos gêneros, fornecidos descrições e comentários sobre cada um deles, com distribuição geográfica, número de espécies no Brasil e no Estado do Rio de Janeiro, como também é disponibilizada uma lista preliminar das espécies ocorrentes no Estado.
\end{abstract}

Palavras-chave: taxonomia, sinopse, Lauraceae, Rio de Janeiro, Brasil

\begin{abstract}
Taxonomic synopsis of the family Lauraceae in the Rio de Janeiro State, Brazil). The present work consists of a taxonomic synopsis of the genera of the family Lauraceae in the Rio de Janeiro State, Brazil. It was verified the occurrence of about 109 species of 16 genera: Aniba Aubl., Aiouea Aubl., Beilschmiedia Nees, Cassytha L., Cinnamomum Schaeff., Cryptocarya R. Br., Endlicheria Nees, Licaria Aubl., Mezilaurus Kuntze ex Taub., Nectandra Rol. ex Rottb., Ocotea Aubl., Persea Mill., Phyllostemonodaphne Kosterm., Pleurothyrium Nees, Rhodostemonodaphne Rohwer \& Kubitzki, Urbanodendron Mez. A key was elaborated for identification of genera, and also descriptions and comments on each one of them, with geographical distribution, number of species in Brazil and in the Rio de Janeiro State, and a preliminary list of the species that occur in the State.
\end{abstract}

Key words : taxonomy, synopsis, Lauraceae, Rio de Janeiro State, Brazil

\section{Introdução}

As Lauraceae têm distribuição pantropical sendo bem representadas na América, Ásia tropical, Austrália e Madagascar e pouco expressivas no sul da África, possuindo cerca de 2.500 espécies subordinadas a 50 gêneros (Rohwer 1993). No Brasil ocorrem 22 gêneros que habitam em sua maior parte as Florestas Pluviais e também as Restingas e os Cerrados (Barroso 2002). No Estado do Rio de Janeiro são registradas até o momento cerca de 109 espécies distribuídas em 16 gêneros.

Trabalhos clássicos sobre a taxonomia das Lauraceae foram elaborados por Meissner (1864; 1866), Mez (1889) e Nees (1833; 1836). Nos neotrópicos são relevantes os de Allen (1945; 1966), Kopp (1966), Kostermans (1936; 1937; 1938 a; 1938b; 1952; 1953; 1957; 1961; 1970/1974), Kubitzki \& Renner (1982), Kurz (1983), Werff (1984; 1987; 1991; 1993;
1994), Werff \& Richter (1996), Rohwer (1986; 1988; 1993a; 1993b), Lorea-Hernández (1998), Nishida (1999), Chanderbali (2004) e Madriñàn (2004). Dentre os estudos realizados no Brasil destacam-se os de Vattimo-Gil (1956a; 1956b; 1956c; 1957; 1958; 1959a; 1959b-1961a; 1960-1961b; 1966a; 1966b; 1976; 1979), Coe-Teixeira $(1963 ; 1965 ; 1967 ; 1975 ; 1980)$, Baitello \& Coe-Teixeira (1987) e mais recentemente os de Quinet \& Andreata (2002) e Baitello (2003).

Este tema foi escolhido levando-se em conta a expressividade das Lauraceae, tanto aos níveis genérico, quanto específico, na composição da flora arbórea em Floresta Pluvial Atlântica do Estado do Rio de Janeiro, registrada por diversos autores (Kurtz 2000; Vaz 1992; Rodrigues 1996; Guedes-Brunni et al. 1997), aliado ao grande número de plantas deste grupo que vêm sendo coletadas e a sua complexidade morfológica e taxonômica, que dão à família a reputação de grupo de difícil identificação.

\footnotetext{
1 Instituto de Pesquisas Jardim Botânico do Rio de Janeiro, Rua Pacheco Leão 915, CEP 22460-030, Jardim Botânico, Rio de Janeiro, RJ, Brasil (aquinet@jbrj.gov.br)
} 
Este trabalho objetiva fornecer um panorama atualizado sobre a família Lauraceae, disponibilizando chave para gêneros e lista preliminar das espécies ocorrentes no Estado do Rio de Janeiro, de modo a contribuir para o conhecimento da diversidade de sua flora.

\section{Material e métodos}

As descrições da família e dos gêneros foram baseadas na bibliografia disponível, incluindo trabalhos clássicos e as revisões mais recentes, bem como na análise dos espécimes coletados no Estado do Rio de Janeiro.

A chave de gêneros foi confeccionada com base em caracteres morfológicos, com ênfase nos florais, principalmente do androceu.

A lista de espécies foi elaborada por meio de consultas às coleções depositadas nos herbários do Estado do Rio de Janeiro (FCAB, RB, RUSU, GUA, HB, R, RBR), cujas siglas seguem Holmgren et al. (1990), e de literatura especializada.

\section{Resultados e discussão}

Lauraceae Juss., Gen. Pl. 89. 1789.

Árvores ou arbustos, com exceção de Cassytha, esta trepadeira parasita. Em geral plantas aromáticas, monóicas, dióicas ou ginodióicas. Folhas alternas, raramente opostas à subopostas (Beilschmiedia), com pecíolo em geral canaliculado, lâmina de margem saliente, às vezes revoluta, nervação camptódroma, broquidódroma ou acródroma (Cinnamomum), presença de células oleaginosas e mucilaginosas no mesofilo, glabras ou indumento com tricomas simples e unicelulares. Inflorescência axilar ou terminal, em panícula, tirso, tirsóide, botrióide, espiga ou racemo. Flores monóclinas ou díclinas, tépalas em geral 6 ou 9 , neste último caso as mais internas de origem estaminodial (Phyllostemonodaphne), iguais, ou as externas bem menores que as internas (Persea, Cassytha). Androceu com 3, 6 ou em geral 9 estames férteis, anteras bilocelares ou quadrilocelares, dispostas em 4 séries: $1^{\mathrm{a}}$ e $2^{\mathrm{a}}$ séries de estames com anteras introrsas, extrorso-apicais ou lateral - extrorsas; $3^{\mathrm{a}}$ série de estames com um par de glândulas na base dos filetes, anteras em geral extrorsas; raramente todos os estames das $1^{\mathrm{a}}, 2^{\mathrm{a}}$ e $3^{\mathrm{a}}$ séries com um par de glândulas na base dos filetes (Urbanodendron); $4^{\mathrm{a}}$ série mais interna estaminodial, filiforme, triangular, cordada, sagitada ou ausente. Flores díclinas em plantas dióicas, as estaminadas com pistilóide reduzido ou ausente e as pistiladas com estaminódios reduzidos e de morfologia semelhante aos estames das flores estaminadas. Gineceu com ovário mediano ou súpero, unicarpelar, unilocular, estilete simples, terminal, óvulo único, pêndulo, anátropo. Fruto bacáceo, exocarpo fino, mesocarpo carnoso, pouco ou muito espesso, endocarpo representado apenas pela epiderme interna da parede do fruto; sobre ou parcialmente envolvido pelo hipanto modificado em cúpula, ou esta ausente (Beilschmiedia), com margem simples ou dupla, tépalas persistentes ou decíduas, ou fruto completamente envolvido pelo perigônio acrescente formando uma núcula (Cryptocarya), pedicelo frutífero às vezes muito espessado. Semente sem endosperma, embrião desenvolvido, rostelo curto, cotilédones amplos, carnosos.

Chave de identificação para os gêneros

1. Trepadeiras; parasitas; folhas escamiformes

4. Cassytha

1. Árvores ou arbustos; não parasitas; folhas desenvolvidas

2. Flores monoclinas

3. Flor com 9 estames férteis

4. Estames da $3^{\text {a }}$ série com par de glândulas na base dos filetes muito desenvolvidos, às vezes fusionados 14. Pleurothyrium

4. Estames da $3^{a}$ série com par de glândulas na base dos filetes menos desenvolvidos, nunca fusionados

5. Todos os estames com um par de glândulas 16. Urbanodendron

5. Somente os estames da $3^{a}$ série com um par de glândulas

6. Anteras bilocelares

7. Folhas opostas a subopostas.

3. Beilschmiedia

7. Folhas alternas 
8. Estames da $1^{\mathrm{a}}$ e $2^{\mathrm{a}}$ séries com deiscência introrsa ou extrorsoapical, filetes em geral de largura semelhante à das anteras

2. Aniba

8. Estames da $1^{\mathrm{a}}$ e $2^{\mathrm{a}}$ séries com deiscência introrsa ou lateral extrorsa, filetes mais estreitados que as anteras

9. Flores com hipanto urceolado, comprimido abaixo das tépalas; tépalas em geral patentes; estaminódios da $4^{\text {a }}$ série cordato-ovados, sagitados ou foliáceos; fruto núcula

6. Cryptocarya

9. Flores com hipanto obcônico, cilíndrico ou campanulado, não comprimido abaixo das tépalas; tépalas eretas; estaminódios da $4^{\mathrm{a}}$ série estipiformes, triangulares ou clavados; fruto bacáceo

1. Aiouea

6. Anteras quadrilocelares

10. Estaminódios da $4^{a}$ série bem desenvolvidos, cordados ou sagitados

11. Folhas acródromas

5. Cinnamomum

11. Folhas peninérveas

12. Estames com filetes maiores que as anteras

12. Persea

12. Estames com filetes menores que as antera

11.Ocotea

10. Estaminódios da $4^{\mathrm{a}}$ série ausentes ou quando presentes reduzidos, em geral filiformes

13. Locelos superpostos

11. Ocotea

13. Locelos dispostos em arco 10. Nectandra

3. Flor com 3 ou 6 estames férteis

14. Flor com 6 estames férteis

15. Estames da $1^{\text {a }}$ série transformados em estaminódios petalóides ... 13. Phyllostemonodaphne

15. Estames da $1^{\text {a }}$ série férteis 1. Aiouea

14. Flor com 3 estames férteis

16. Estames da $3^{\text {a }}$ série férteis

17. Folhas congestas no ápice dos ramos; inflorescências em panículas com terminações racemosas; cúpula quando presente pequena em relação ao fruto e de margem simples

. Mezilaurus

17. Folhas laxas no ápice dos ramos; inflorescências em panículas com terminações cimosas; cúpula grande em relação ao fruto e de margem dupla

8. Licaria

16. Estames da $1^{\text {a }}$ série férteis

1. Aiouea

2. Flores diclinas

18. Estames das flores estaminadas com anteras bilocelares; estaminódios das flores pistiladas com vestígios de anteras bilocelares

7. Endlicheria

18. Estames das flores estaminadas com anteras quadrilocelares; estaminódios das flores pistiladas com vestígios de anteras quadrilocelares

19. Estaminódios das flores pistiladas com vestígio de locelos; estames das flores estaminadas com locelos dispostos no mesmo nível ou em arco 15. Rhodostemonodaphne

19. Estaminódios das flores pistiladas com vestígio de locelos; estames das flores estaminadas com locelos dispostos em dois pares superpostos

11. Ocotea

\section{Aiouea Aubl., Hist. Pl. Guiane 1: 310. 1775.}

Árvores monóicas. Folhas alternas, sem papilas na epiderme abaxial. Inflorescência em panícula ou tirsóide. Flores monoclinas, hipanto obcônico, cilíndrico ou campanulado, não comprimido abaixo das tépalas, tépalas 6, eretas, iguais, face interna sem papilas. Androceu em geral com 9, 6 ou 3 estames férteis, filetes mais delgados que as anteras, anteras bilocelares: $1^{\mathrm{a}}$ série com 3 estames, anteras introrsas ou lateralextrorsas; $2^{2}$ série com 3 estames, anteras introrsas ou lateral-extrorsas ou estaminodiais; $3^{a}$ série com 3 estames, par de glândulas na base dos filetes, reduzidos, nunca fusionados, anteras extrorsas ou estaminodiais; $4^{\mathrm{a}}$ série estaminodial, com 3 estaminódios estipiformes, triangulares ou clavados. Fruto bacáceo, elipsóide, sobre ou parcialmente envolvido por cúpula de margem 
simples, lenhosa, tépalas decíduas.

Aiouea é constituído por 19 espécies distribuídas na América Central e América do Sul (Kubitzki \& Renner 1982). No Brasil é registrada a ocorrência de 14 espécies, distribuídas principalmente na Região Sudeste. No Estado do Rio de Janeiro são reconhecidas três espécies: A. acarodomatifera Kosterm., A. laevis (Mart.) Kosterm. e A. saligna Meisn.

\section{Aniba Aubl., Hist. Pl. Guiane 1: 327. 1775.}

Árvores ou arvoretas, monóicas. Folhas alternas, em geral com papilas na epiderme abaxial. Inflorescência geralmente panícula ou botrióide. Flores monoclinas, hipanto cupuliforme ou tubular, não comprimido abaixo das tépalas, tépalas 6 , eretas, iguais, face interna sem papilas. Androceu com 9 estames férteis, filetes em geral da mesma largura que as anteras, anteras bilocelares: $1^{\mathrm{a}}$ e $2^{\mathrm{a}}$ séries com 3 estames cada, anteras introrsas ou extrorso-apicais; $3^{a}$ série com 3 estames, par de glândulas na base dos filetes, reduzidos, nunca fusionados, anteras extrosas; $4^{\text {a }}$ série estaminodial ausente ou raro 3 estaminódios filiformes. Fruto bacáceo, elipsóide ou ovóide, envolvido parcialmente por cúpula de margem simples, hemisférica, lenhosa, tépalas decíduas.

Aniba apresenta cerca de 41 espécies distribuídas na América Central, Antilhas e principalmente na América do Sul. O centro de diversidade das espécies encontra-se na região das Guianas e Amazônia Central (Kubitzki \& Renner 1982). No Brasil, o gênero é representado por 26 espécies, das quais duas ocorrem no Estado do Rio de Janeiro, A. firmula (Nees \& Mart.) Mez e A. pedicellata Kosterm.

3. Beilschmiedia Nees in Wall., Pl. Asiat. Rar. 2: 69. 1831.

Árvores monóicas. Folhas opostas a subopostas, sem papilas na epiderme abaxial. Inflorescência em panícula ou tirsóide. Flores monoclinas, hipanto achatado, ciatiforme, não comprimido abaixo das tépalas, tépalas 6 , eretas, iguais, face interna sem papilas. Androceu com 9 estames férteis, filetes mais delgados que as anteras ou ausentes, anteras bilocelares: $1^{\mathrm{a}}$ e $2^{\mathrm{a}}$ séries com 3 estames cada, anteras introrsas; $3^{\mathrm{a}}$ série com 3 estames, par de glândulas na base do filetes, reduzidos, nunca fusionados, anteras extrorsas; $4^{a}$ série estaminodial ausente ou presente com 3 estaminódios sagitados. Fruto bacáceo, elipsóide ou esférico, cúpula ausente.

Beilschmiedia compreende cerca de 250 espécies (Nishida 1999), de distribuição pantropical, na América desde a região central do México até o sudoeste do Brasil (Nishida 1999), e na África, Ásia, Malásia, Austrália, Ilhas do Pacífico e Nova Zelândia, (Hyland 1989). Nos neotrópicos engloba 28 táxons (Nishida 1999). No Brasil ocorrem oito espécies de forma disjunta, uma na região Amazônica e as demais na Região Sudeste. O Estado do Rio de Janeiro é o centro de diversidade do gênero no Brasil, onde ocorrem as seis das sete espécies encontradas na região Sudeste: B. angustifolia Kosterm., B. emarginata (Meisn.) Kosterm., B. fluminensis Kosterm., B. rigida (Mez) Kosterm., B. stricta Kosterm., B. taubertiana (Schwacke \& Mez) Kosterm.

\section{Cassytha L., Sp. Pl. 1: 35. 1753.}

Trepadeiras volúveis, parasitas, com pequenos haustórios, monóicas. Folhas alternas escamiformes, sem papilas na epiderme abaxial. Inflorescência em panículas, espigas racemos, ou reduzidas. Flores monoclinas, hipanto urceolado, não comprimido abaixo das tépalas, tépalas 6 , desiguais, face interna sem papilas, as externas menores que as internas, semelhantes às brácteas involucrais, persistentes. Androceu com 9 estames férteis, filetes mais delgados que as anteras, anteras bilocelares: $1^{\mathrm{a}} \mathrm{e} 2^{\mathrm{a}}$ séries com 3 estames cada, anteras introrsas; $3^{\text {a }}$ série com 3 estames, par de glândulas na base dos filetes, reduzidos, nunca fusionados, anteras extrorsas; $4^{\text {a }}$ série estaminodial presente, com 3 estaminódios triangulares ou glanduliformes. Fruto constituído por uma núcula globosa, completamente incluso no hipanto expandido, de consistência carnosa, que o envolve completamente, ápice do fruto com pequeno orifício, tépalas persistentes.

Cassytha contém 17 espécies, cuja maioria habita a Austrália e algumas a África e Ásia (Weber 1981). No Estado do Rio de Janeiro ocorre a única espécie de distribuição pantropical do gênero, $C$. filiformis $\mathrm{L}$.

5. Cinnamomum Schaeff. Bot. Exped. 74: 268-269. 1760.

Árvores monóicas. Folhas alternas, acródromas, sem papilas na epiderme abaxial. Inflorescência em panícula, tirsóide ou tirso. Flores monoclinas, hipanto urceolado ou campanulado, não comprimido abaixo das tépalas, tépalas 6 , eretas, iguais, face interna raro densamente papilosas. Androceu com 9 estames férteis, filetes mais delgados que as anteras, anteras em geral quadrilocelares ou raro bilocelares na $3^{\mathrm{a}}$ série por supressão dos locelos superiores: $1^{\mathrm{a}}$ e $2^{\mathrm{a}}$ séries com 3 estames cada, anteras introrsas; $3^{\text {a }}$ série com 3 
estames, par de glândulas na base dos filetes, reduzidos, nunca fusionados, anteras extrorsas; $4^{a}$ série estaminodial presente, bem desenvolvida, com 3 estaminódios cordados ou sagitados. Fruto bacáceo, elipsóide ou subgloboso, em geral pouco desenvolvido,cúpula de margem simples, tépalas persistentes ou decíduas.

Cinnamomum contém de 200-350 espécies distribuídas principalmente no sudeste da Ásia, na Índia, Austrália e Ilhas do Pacífico (Rohwer 1993b). No neotrópico o gênero é constituído por cerca de 50 espécies, ocorrendo desde o México central até o sul do Brasil, Paraguai e norte da Argentina. No Brasil o gênero é representado por cerca de 15 espécies e no Estado do Rio de Janeiro são aceitas até o momento quatro espécies: C. glaziovii Mez, C. riedelianum Kosterm., C. tomentulosum Kosterm., C. triplinerve (Ruiz \& Pav.) Kosterm.

6. Cryptocarya R. Br., Prodr. 1: 402. 1810.

Árvores monóicas. Folhas alternas, em geral sem papilas na epiderme abaxial. Inflorescência em panícula ou tirsóide. Flores monoclinas, hipanto urceolado, comprimido abaixo das tépalas, tépalas 6 , em geral patentes, iguais, face interna sem papilas. Androceu com 9 estames férteis, anteras bilocelares; filetes mais delgados que as anteras: $1^{\mathrm{a}}$ e $2^{\mathrm{a}}$ séries com 3 estames cada, anteras introrsas; $3^{a}$ série com 3 estames, par de glândulas na base dos filetes, reduzidos, nunca fusionados, ou dispostas entre as $1^{\mathrm{a}}, 2^{\mathrm{a}}$ e $3^{\mathrm{a}}$ séries de estames, anteras extrorsas; $4^{\text {a }}$ série estaminodial presente, com 3 estaminódios, cordato-ovados, sagitados ou foliáceos. Fruto constituído por uma núcula globosa, pericarpo espessado, consistência firme, superfície lisa ou estriada; hipanto acrescente, consistência carnosa, superfície lisa ou sulcada, que envolve completamente a núcula; no ápice umbonado do fruto, a margem do hipanto e estames são em geral persistentes (apenas em frutos imaturos).

Cryptocarya apresenta cerca de 350 espécies, cujo centro de diversidade está localizado na Malásia, não havendo registros na África Central (Rohwer 1993b). No neotrópico o gênero tem sete espécies de distribuição restrita a América do Sul, ocorrendo no Brasil, Guiana Francesa e no Chile (Kostermans 1937). No Brasil são reconhecidas dez espécies, uma na região amazônica, principalmente no estado do Pará e as demais registradas na região sudeste (Kostermans 1937; 1938). No Estado do Rio de Janeiro são reconhecidas oito espécies: C. aschersoniana Mez, Cryptocarya granulata Vattimo-Gil, Cryptocarya jacarepaguensis Vattimo-Gil, C. micrantha Meisn., C. minima Mez, C. moschata Nees \& Mart. ex Nees, Cryptocarya nigropunctata Vattimo-Gil e C. saligna Mez.

\section{Endlicheria Nees, Linnaea 8: 37. 1833.}

Árvores, dióicas. Folhas alternas, sem papilas na epiderme abaxial. Inflorescência em panícula ou tirsóide. Flores diclinas, hipanto urceolado, não comprimido abaixo das tépalas, tépalas 6 , eretas, iguais, face interna sem papilas. Flores estaminadas: androceu com 9 estames férteis, filetes mais delgados que as anteras ou ausentes, anteras bilocelares: as das $1^{\text {a }}$ e $2^{\text {a }}$ séries com 3 estames cada, anteras introrsas; $3^{\text {a }}$ série com 3 estames, par de glândulas na base dos filetes, reduzidos, nunca fusionados, anteras extrorsas ou lateral extrorsas; $4^{\text {a }}$ série estaminodial ausente; pistilóide presente ou ausente. Flores pistiladas: estaminódios reduzidos, de morfologia semelhante aos estames das flores estaminadas, com vestígios de anteras bilocelares. Fruto bacáceo, elipsóide, cúpula de margem simples, rasa, tépalas decíduas raro persistentes.

Endlicheria tem cerca de 60 espécies distribuídas na América Tropical (Chanderbali 2004). No Estado do Rio de Janeiro são registradas as ocorrências de duas espécies: Endlicheria glomerata Mez, E. paniculata (Spreng.) Macbride.

Chanderbali na revisão das espécies neotropicais do gênero exclui Endlicheria balsamea Vattimo-Gil, apontando como espécie duvidosa e provavelmente posicionada no gênero Aiouea.

\section{Licaria Aubl., Hist. Pl. Guiane 1: 313. 1775.}

Árvores monóicas. Folhas alternas ou opostas, laxas no ápice dos ramos, sem papilas na epiderme abaxial das folhas. Inflorescência em panícula com terminações cimosas. Flores monoclinas, hipanto urceolado, não comprimido abaixo das tépalas, tépalas 6 , em geral eretas, iguais face interna sem papilas. Androceu com 3 estames férteis, filetes em geral da mesma largura que anteras ou mais delgados, anteras bilocelares: $1^{\mathrm{a}}$ e $2^{\mathrm{a}}$ séries com estames ausentes ou transformados em estaminódios; $3^{\text {a }}$ série com 3 estames, par de glândulas na base dos filetes presentes, reduzidos, nunca fusionados, ou ausentes, anteras introrsas ou extrorso-apicais; $4^{\text {a }}$ série estaminodial ausente ou raro presente, com 3 estaminódios. Fruto bacáceo, parcialmente envolvido por cúpula grande em relação ao fruto, de margem dupla, tépalas decíduas. 
Licaria é um gênero neotropical que consiste de 38 espécies distribuídas desde o sul da Flórida, México até o sudoeste do Brasil e Bolívia. No Brasil é registrada a ocorrência de 20 espécies e duas subespécies, na sua maioria na região amazônica (Kurz 2000). No Estado do Rio de Janeiro são reconhecidas duas espécies: L. armeniaca (Nees) Kosterm. e L. guianensis Aubl.

9. Mezilaurus Kuntze ex Taub., Bot. Centralbl. 50: 21. 1892.

Árvores monóicas. Folhas alternas, em geral congestas no ápice dos ramos, sem papilas na epiderme abaxial. Inflorescência em panícula com terminações racemosas. Flores monoclinas, hipanto urceolado, não comprimido abaixo das tépalas, tépalas 6 , em geral eretas, iguais, face interna sem papilas. Androceu com 3 estames férteis, filetes mais delgados ou indiferenciados das anteras, anteras bilocelares (nas espécies brasileiras): $1^{\text {a }}$ e $2^{\text {a }}$ séries com estames ausentes; $3^{\text {a }}$ série com 3 estames, pares de glândulas na base dos filetes (ausentes nas espécies brasileiras), reduzidos, nunca fusionados, anteras extrorsas ou apical-extrorsas, em geral exsertas; $4^{\text {a }}$ série estaminodial ausente. Fruto bacáceo, cúpula quando presente pateliforme, pequena em relação ao fruto, de margem única, tépalas decíduas.

Mezilaurus é um gênero neotropical que consiste de 18 espécies que ocorrem desde a Costa Rica até o sudeste do Brasil (Werff 1987). No Brasil são apontadas 13 espécies distribuídas na sua maioria na região amazônica. No Estado do Rio de Janeiro é registrada somente ocorrência de $M$. navalium (Allemão) Taub. ex Mez.

10. Nectandra Rol. ex Rottb., Acta Lit. Univ. Hafn.1: 279. 1778.

Árvores ou arbustos, monóicos. Folhas alternas, raro subopostas a opostas, em geral sem papilas na epiderme abaxial. Inflorescência tirsóide ou panícula. Flores monoclinas, hipanto urceolado, não comprimido abaixo das tépalas, tépalas 6 , em geral reflexas, iguais, face interna densamente papilosas. Androceu com 9 estames férteis, filetes em geral da mesma largura que as anteras ou mais delgados, muito curtos ou ausentes, anteras quadrilocelares, papilosas, locelos dispostos em arco: $1^{\mathrm{a}}$ e $2^{\mathrm{a}}$ séries com 3 estames cada, anteras introrsas; $3^{\mathrm{a}}$ série com 3 estames, par de glândulas na base dos filetes, reduzidos, nunca fusionados, anteras extrorsas; 4 série estaminodial ausente ou quando presente com 3 estaminódios, reduzidos, em geral filiformes. Fruto bacáceo, elipsóide ou sub-globoso, parcialmente envolvido por cúpula lenhosa ou sobre cúpula discóide, de margem simples, tépalas decíduas.

Nectandra tem cerca de 118 espécies distribuídas na América tropical e subtropical, incluíndo as Antilhas. $O$ centro de diversidade se encontra nas falhas orientais dos Andes e da região da Amazônia Peruana (Rohwer 1993a). É o segundo maior gênero da família com cerca de 42 espécies no Brasil e no Estado do Rio de Janeiro é registrada a ocorrência de doze espécies: $N$. debilis Mez, $N$. lanceolata Nees, $N$. leucantha Nees, $N$. membranacea (Sw.) Griseb., N. megapotamica (Spreng.) Mez, N. nitidula Nees, N. oppositifolia Nees, N. psammophila Nees, N. puberula (Schott) Nees, N. reticulata (Ruiz \& Pav.) Mez, N. spicata Meisn., N. weddellii Meisn.

\section{Ocotea Aubl., Hist. Pl. Guiane 2: 780. 1775.}

Árvores ou arbustos, monóicos, dióicos ou ginodióicos. Folhas alternas, raro subopostas ou verticiladas, sem papilas na epiderme abaxial. Inflorescência ou sinflorescência em panícula, tirso, tirsóide ou botrióide. Flores monoclinas ou diclinas, hipanto achatado ou tubular, não comprimido abaixo das tépalas, tépalas 6 , eretas ou patentes, iguais ou raro desiguais, face interna raro densamente papilosas. Flores estaminadas: androceu com 9 estames férteis, filetes em geral mais delgados, menores ou maiores que as anteras, anteras quadrilocelares, locelos dispostos em pares superpostos: $1^{\mathrm{a}}$ e $2^{\mathrm{a}}$ séries com 3 estames cada, anteras introrsas; $3^{\mathrm{a}}$ série com 3 estames, par de glândulas na base dos filetes, reduzidos, nunca fusionados, anteras extrorsas; $4^{\mathrm{a}}$ série estaminodial ausente ou presente, com 3 estaminódios, em geral reduzidos, filiformes, ou raramente com estaminódios bem desenvolvidos, cordados ou sagitados; pistilóide presente ou ausente. Flores pistiladas com estaminódios reduzidos, de morfologia semelhante aos estames das flores estaminadas, com vestígio de locelos dispostos em dois pares superpostos. Fruto bacáceo, sobre ou parcialmente envolvido pela cúpula, em geral com margem simples e tépalas decíduas.

Ocotea é constituído por cerca de 350 espécies distribuídas na América tropical e subtropical, desde o México até a Argentina, ocorrendo também em Madagascar, na África e nas Ilhas Canárias (Rohwer 1993b). Algumas das espécies que ocorrem no Estado do Rio de Janeiro foram agrupadas, por Rohwer (1986), em complexos, que muitas vezes reúnem um grande número táxons, sendo que alguns destes, necessitam 
de estudos mais aprofundados com análise de exemplares tipo, bem como, o maior número possível de material botânico, para melhor delimitação da amplitude morfológica e da distribuição geográfica dessas espécies. São reconhecidas para o Estado do Rio de Janeiro até o momento 52 espécies com base na literatura e coleções examinadas: $O$. aciphylla (Nees) Mez, O. aniboides Mez, Ocotea areolata Mez, Ocotea argentea Mez, O. beyrichii (Nees) Mez, O. brachybotra (Meisn.) Mez, $O$. catharinensis Mez, O. confertiflora (Meisn.) Mez, O. corymbosa (Meisn.) Mez, O. daphnifolia (Meisn.) Mez, O. diospyrifolia (Meisn.) Mez, $O$. divaricata (Nees) Mez, O. dispersa (Nees) Mez, $O$. domatiata Mez, O. elegans Mez, O. fasciculata (Nees) Mez, O. floribunda (Sw.) Mez, O. glauca (Nees) Mez, O. glaziovii Mez, O. indecora (Schott) Mez, $O$. insignis Mez, O. itatiaiae Vattimo- Gil, $O$. kostermansiana Vattimo-Gil, O. lanata (Nees) Mez, O. lancifolia (Schott) Mez, O. langsdorffii (Meisn.) Mez, O. laxa (Nees) Mez, Ocotea martiana Mez, O. microneura (Meisn.) Rohwer, O. notata (Nees) Mez, O. nunesiana (Vattimo-Gil) Baitello, O. odorifera (Vell.) Rohwer, O. polyantha (Nees) Mez, O. porosa (Nees) Barroso, O. puberula (Rich.) Nees, O. pulchella (Nees) Mez, O. pulchra Vattimo-Gil, Ocotea sassafras (Meisn.) Mez, O. schwackeana Mez, O. schottii (Meisn.) Mez, O. silvestris VattimoGil, O. spectabilis (Meisn.) Mez, O. spixiana (Nees) Mez, O. sulcata Vattimo-Gil, O. tabacifolia (Meisn.) Rohwer, O. teleiandra (Meisn.) Mez, O. tenuiflora (Nees) Mez, O. vaccinioides (Meisn.) Mez, O. villosa Kosterm., O. velloziana (Meisn.) Mez, O. velutina (Nees) Rohwer, O. urbaniana Mez.

As espécies registradas para o Estado do Rio de Janeiro, porém consideradas genericamente dúbias por Rohwer (1996), não puderam ser identificadas por estarem representadas apenas por material vegetativo ou com flores imaturas. É o caso de $O$. abbreviata Schwacke \& Mez, O. arechavaletae Mez, $O$. sinaiana Vattimo-Gil e O. megaphylla Meisn., esta representada somente pelo material tipo apenas em estado frutífero.

\section{Persea Mill., Gard. Dict., ed. 4: 1030. 1754.}

Árvores monóicas. Folhas alternas, peninérveas, sem papilas na epiderme abaxial. Inflorescência tirsopaniculada. Flores monoclinas, hipanto curto, achatado, não comprimido abaixo das tépalas, tépalas 6 , eretas, iguais ou desiguais, as externas menores que as internas, face interna raro densamente papilosas.
Androceu com 9 ou 6 estames férteis, filetes mais delgados e maiores que as anteras, anteras quadrilocelares: os das $1^{\mathrm{a}}$ e $2^{\mathrm{a}}$ séries com 3 estames cada, anteras introrsas ou com locelos inferiores lateralmente extrorsos; $3^{\text {a }}$ série com 3 estames, par de glândulas na base dos filetes, reduzidos, nunca fusionados, anteras extrorsas ou com locelos inferiores lateralmente extrorsos; $4^{\mathrm{a}}$ série estaminodial presente, com 3 estaminódios, cordados ou sagitados, pedicelados. Fruto bacáceo, cúpula de margem simples, tépalas em geral persistentes.

Persea apresenta cerca de 200 espécies, com distribuição na Ásia e na América Tropical e temperada (Kopp 1966). No Brasil o gênero é constituído por 19 espécies e no Estado do Rio de Janeiro por nove espécies, a saber: $P$. alba Nees \& Mart. ex Nees, $P$. aurata Miq., P. caesia Meisn., P. fulva Kopp var. fulva, P. major Kopp, P. microphyla Mez, P. pyrifolia Nees \& Mart. ex Nees, P. rufotomentosa Nees \& Mart. ex Nees e $P$. venosa Nees \& Mart. ex Nees.

13. Phyllostemonodaphne Kosterm., Recueil Trav. Bot. Néerl. 33: 754. 1936.

Árvores monóicas. Folhas alternas, sem papilas na face abaxial das folhas. Inflorescência botrióide. Flores monoclinas, hipanto urceolado, não comprimido abaixo das tépalas, tépalas 9 , eretas, face interna sem papilas, as mais internas de origem estaminodial. Androceu com 6 estames férteis, filetes mais delgados que anteras, todos providos de par de glândulas, anteras bilocelares: $1^{\mathrm{a}}$ série estaminodial transformada na série mais interna de tétalas; $2^{\mathrm{a}}$ série com 3 estames, anteras introrsas; $3^{\text {a }}$ série com 3 estames, par de glândulas na base dos filetes, reduzidos, nunca fusionados, anteras extrorsas; $4^{\mathrm{a}}$ série estaminodial presente, reduzida, com 3 estaminódios, ou ausente. Fruto bacáceo, sobre cúpula de margem dupla, tépalas decíduas.

Phyllostemonodaphne é um gênero monotípico representado por P. geminiflora (Mez) Kosterm. Ocorre nos Estados de Minas Gerais e principalmente no Rio de Janeiro na Floresta Pluvial Atlântica (Rohwer 1988).

14. Pleurothyrium Nees in Lindl., Nat. Syst. Bot., ed. 2: 442.1836.

Árvores monóicas. Folhas alternas, sem papilas na epiderme abaxial. Inflorescência tirso-paniculada. Flores monoclinas, hipanto urceolado, não comprimido abaixo das tépalas, tépalas 6 , em geral eretas ou reflexas, iguais, face interna com ou sem papilas. Androceu com 9 estames férteis, filetes em geral mais 
delgados que anteras, anteras quadrilocelares: $1^{\mathrm{a}}$ e $2^{\mathrm{a}}$ séries com 3 estames cada, anteras com um par de lóculos com deiscência lateral e um par introrso; $3^{\text {a }}$ série com 3 estames, par de glândulas na base dos filetes, muito desenvolvidos, às vezes fusionados, anteras com um par de locelos extrorsos e um par lateral-extrorso; 4a série estaminodial presente, reduzida, com 3 estaminódios, ou ausente. Fruto bacáceo, parcialmente envolvido por cúpula de margem simples, tépalas decíduas ou persistentes.

Pleurothyrium é constituído por 40 espécies de distribuição neotropical ocorrendo na Panamá, Guatemala, Honduras, Nicarágua, Costa Rica, Colômbia, Venezuela, Equador, Peru, Bolívia e no Brasil, onde é representado por 13 espécies, e no Estado do Rio de Janeiro, apenas por P. amplifolium (Mez) Rohwer (Werff 1993).

15. Rhodostemonodaphne Rohwer \& Kubitzki, Bot. Jahrb. Syst. 107: 135. 1985.

Árvores dióicas. Folhas alternas, sem papilas na epiderme abaxial. Inflorescência paniculada, pistilada pauciflora, estaminada multiflora. Flores diclinas, hipanto tubular, não comprimido abaixo das tépalas, tépalas 6 , em geral patentes, iguais, face interna em geral sem papilas. Flores estaminadas: androceu com 9 estames férteis, filetes mais delgados ou da mesma largura que anteras, anteras quadrilocelares, locelos dispostos no mesmo nível ou em arco: $1^{\mathrm{a}}$ e $2^{\mathrm{a}}$ séries com 3 estames cada, anteras introrsas; $3^{a}$ série com 3 estames, par de glândulas volumosas na base dos filetes, nunca fusionados, anteras extrorsas; $4^{\text {a }}$ série estaminodial ausente; pistilóide presente ou ausente. Flores pistiladas: ovário elipsóide ou globoso, estaminódios reduzidos, de morfologia semelhante aos estames das flores estaminadas, com vestígios de locelos dispostos no mesmo nível ou em arco. Fruto bacáceo, envolvido por cúpula de margem simples, tépalas persistentes ou decíduas.

Rhodostemonodaphne tem cerca de 41 espécies distribuídas na América do sul (Madriñán 2004), sendo representado no Estado do Rio de Janeiro por R. macrocalyx (Meisn.) Rohwer ex Madriñán e $R$. anomala (Mez) Rohwer

16. Urbanodendron Mez, Jahrb. Königl. Bot. Gart. Belin 5: 80. 1889.

Árvores monóicas. Folhas alternas, sem papilas na epiderme abaxial. Inflorescência tirsóide ou botrióide. Flores monoclinas, hipanto urceolado, não comprimido abaixo das tépalas, tépalas 6 , iguais, face interna sem papilas. Androceu com 9 estames férteis, todos os estames com par de glândulas na base dos filetes, reduzidas, nunca fusionadas, filetes mais delgados que as anteras; anteras quadrilocelares ou bilocelares: $1^{\mathrm{a}}$ e $2^{\mathrm{a}}$ séries com 3 estames cada, anteras introrsas ou lateralmente extrorsas; $3^{\mathrm{a}}$ série com 3 estames, anteras extrorsas; $4^{\mathrm{a}}$ série estaminodial presente reduzida ou ausente. Fruto bacáceo, parcialmente envolvido por cúpula, margem dupla, tépalas decíduas.

Urbanodendron é constituído por três espécies com distribuição restrita aos Estados de Minas Gerais, Espírito Santo e Rio de Janeiro, onde todas ocorrem (Rohwer 1988). São elas: U. bahiense (Meisn.) Rohwer, U. macrophyllum Rower e U. verrucosum (Nees) Mez.

\section{Referências bibliográficas}

Allen, C.K. 1945. Studies in the Lauraceae VI. Preliminary survey of the Mexican and Central American species. Journal of the Arnold Arboretum 26: 280-434.

Allen, C.K. 1966. Notes on Lauraceae of Tropical America I. The generic status of Nectandra, Ocotea and Pleurothyrium. Phytologia 13(3): 221-231.

Baitello, J.P. \& Coe-Teixeira, B. 1987. Flora Fanerogâmica do Parque Estadual das Fontes do Ipiranga (São Paulo, Brasil): Lauraceae. Hoehnea 14: 63-74.

Baitello, J.P. 2003. Lauraceae. Pp. 149-223. In: H.M. LonghiWagner; V. Bittrich; M.G.L. Wanderley \& G.J. Shepherd (eds.). Flora Fanerogâmica de São Paulo. v.3. São Paulo, Hucitec.

Barroso, G.M.; Guimarães, E.F.; Ichaso, C.L.F.; Costa, C.G. \& Peixoto, A.L. 2002. Sistemática de Angiospermas do Brasil. v.1, 2 ed. Viçosa, Universidade Federal de Viçosa. Chanderbali, A.S. 2004. Lauraceae: Endlicheria. Flora Neotropica, Monograph 91. New York, New York Botanical Garden.

Coe-Teixeira, B. 1963. Lauráceas do Estado de São Paulo I. Beilschmiedia, Endlicheria e Aniba. Boletim do Instituto de Botânica de São Paulo 1: 3-29.

Coe-Teixeira, B. 1965. Lauráceas do Estado de São Paulo II: Cryptocarya. Arquivos de Botânica do Estado de São Paulo 4(1): 1-9.

Coe-Teixeira, B. 1967. Lauráceas do Estado de São Paulo. III. Nectandra. Pp. 119-123. In: Anais do XV Congresso da Sociedade Botânica do Brasil. Porto Alegre, Universidade Federal do Rio Grande do Sul.

Coe-Teixeira, B. 1975. Lauráceas do Estado de São Paulo: Persea. Hoehnea 5: 27-45.

Coe-Teixeira, B. 1980. Lauráceas do gênero Ocotea do Estado de São Paulo. Rodriguésia 32(52): 55-190. 
Guedes-Brunni, R.R. \& Pessoa, S.V.A. \& Kurtz, B. 1997. Florística e estrutura do componente arbustivo-arbóreo de um trecho preservado de floresta montana na Reserva Ecológica de Macaé de Cima. Pp. 127-145. In: H.C. Lima \& R.R Guedes-Bruni (eds.). Serra de Macaé de Cima: Diversidade Florística e Conservação em Mata Atlântica. Rio de Janeiro, Jardim Botânico do Rio de Janeiro.

Holmgrem, P.K.; Holmgrem, N.H. \& Barnett, L.C. 1990. Index Herbariorum. 8. ed. New York, New York Botanical Garden.

Hyland, B.P.M. 1989. A Revision of Lauraceae in Australia (excluding. Cassytha). Australian Systematic Botany 2: 135-367.

Kopp, L.E. 1966. A Taxonomic revision of the genus Persea in the western hemisphere (Perseae - Lauraceae). Memoirs of the New York Botanical Garden 14: 1-120.

Kostermans, A.J.G.H. 1936. Revision of the Lauraceae I. Recueil des Travaux Botaniques Néerlandais 33: 719-757.

Kostermans, A.J.G.H. 1937. Revision of the Lauraceae II. The genera Endlicheria, Cryptocarya (American species) and Licaria. Recueil des Travaux Botaniques Néerlandais 34: 500-609.

Kostermans, A.J.G.H. 1938a. Revision of the Lauraceae III. The genera Aiouea, Systemonodaphne, Urbanodendron, Mezilaurus; additions and corrections to Licaria and Cryptocarya. Recueil des Travaux Botaniques Néerlandais 35: 56-129.

Kostermans, A.J.G.H. 1938b. Revision of the Lauraceae V. A monograph of the genera: Anaueria, Beilschmiedia (American species) and Aniba. Recueil des Travaux Botaniques Néerlandais 35: 834-931.

Kostermans, A.J.G.H. 1952. A historical survey of Lauraceae. Journal of Scientific Research 1: 83-95, 113-127, 141-159.

Kostermans, A.J.G.H. 1953. Notas sobre as Lauraceae Lauroideae Sul Americanas. Boletim Técnico do Instituto Agronômico do Norte 27-30: 49-75.

Kostermans, A.J.G.H. 1957. Lauraceae. Reinwardtia 4(2): 193-256.

Kostermans, A.J.G.H. 1961. Lauraceae. Reinwardtia 6: 21-152.

Kostermans, A.J.G.H. 1970/1974. Materials for a revision of Lauraceae III. Reinwardtia 8: 21-196.

Kubitzki, K. \& Renner, S. 1982. Lauraceae I (Aniba and Aiouea). Flora Neotropica, v.31. New York, New York Botanical Garden.

Kurtz, B.C. 2000. Composição florística e estrutura do estrato arbóreo de um trecho de Mata Atlântica situado na Estação Ecológica Estadual de Paraíso, Município de Cachoeiras de Macacu, Rio de Janeiro, Brasil. Rodriguésia 51(78-79): 69-112.

Kurz, H. 2000. Revision der Gattung Licaria (Lauraceae). Mitteilungen aus dem Institut fur Allgemeine Botanik Hamburg 28/29: 89-221.

Madriñán, S. 2004. Rhodostemonodaphne (Lauraceae). Flora Neotropica. Monograph 92. New York, New York Botanical Garden.
Meissner, C.F. 1864. Lauraceae. Pp. 1-260. In: A.L.P.P. De Candolle (ed.). Prodromus Systematis Naturalis Regni Vegetabilis. v.15. pt. 1 .Victoris Masson et fillii, Parisiis. Meissner, C.F. 1866. Lauraceae et Hernandiaceae. Pp. 137-138. In: C.F.P. Martius \& A.G. Eichler (eds.). Flora Brasiliensis v.5 pt. 2. Muchen, Wien Leipzig.

Mez, C. 1889. Lauraceae Americanae. Jahrbuch des Königlichen botanischen Gartens und des botanichen Museums zu Berlin 5: 1-556.

Nees, C.G.D. 1833. Revisio laurinarum ab Sellowio in Brasilia collectarum et iam in Herbario Regio Berolinensi asservatarum. Linnaea 8(1): 36-51.

Nees, C.G.D. 1836. Systema Laurinarum. Berlin, Veitii et Sociorum, Veitii et Sociorum.

Nishida S. 1999. Revision of Beilschmiedia (Lauraceae) in the Neotropics. Annals of the Missouri Botanical Garden 86: 657-701.

Quinet, A. \& Andreata, H.R.P. 2002. Lauraceae Jussieu na Reserva Ecológica de Macaé de Cima, Município de Nova Friburgo, Rio de Janeiro, Brasil. Rodriguésia 53(82): 59-121.

Rohwer, J.G. 1986. Prodromus einer Monographie der Gattung Ocotea Aubl. (Lauraceae), sensu lato. Mitteilungen aus dem Institut fur Allgemeine Botanik Hamburg 20: 3-278.

Rohwer, J.G. 1988. The genera Dicypellium, Phyllostemonodaphne, Systemonodaphne and Urbanodendron (Lauraceae). Botanisches Jahrbüch für Systematik, Pflanzengeschichte und Pflanzengeographie 110: 157-171.

Rohwer, J.G. 1993a. Lauraceae: Nectandra. Flora Neotropica, v.60. New York, New York Botanical Garden.

Rohwer, J.G. 1993b. Lauraceae. Pp. 366-391. In: K. Kubitzki; J.G. Rohwer \& V. Bittrich (eds.). The Families and Genera of Vascular Plants. v.2. Berlin, Springer-Verlag.

Vattimo-Gil, I. 1956a. O gênero Ocotea Aubl. no sul do Brasil I. Espécies de Santa Catarina e do Paraná. Rodriguésia 18-19(30-31): 265-350.

Vattimo-Gil, I. 1956b. Nota prévia sobre espécies de Ocotea Aubl. (Lauraceae) que ocorrem no Estado do Paraná. Arquivos do Serviço Florestal 10: 109-123.

Vattimo-Gil, I. 1956c. Lauraceae do Itatiaia. Rodriguésia 18-19(30-31): 39-86.

Vattimo-Gil, I. 1957. Lauraceae do Rio de Janeiro. Arquivos do Jardim Botânico do Rio de Janeiro 15: 115-144.

Vattimo-Gil, I. 1958. Seis novas espécies brasileiras do gênero Ocotea Aubl. (Lauraceae). Arquivos do Serviço Florestal 16: 40-46.

Vattimo-Gil, I. 1959a. Flora da Cidade do Rio de Janeiro (Lauraceae). Rodriguésia 21/22(33-34): 157-176.

Vattimo-Gil, I. 1959b-1961a. O gênero Ocotea Aubl. dos Estados de São Paulo e Rio Grande do Sul. Apêndice: notas sobre o gênero Cinnamomum Boehm, no Brasil. Arquivos do Jardim Botânico do Rio de Janeiro 17: 199-226.

Vattimo-Gil, I. 1960-1961b. O gênero Ocotea Aubl. no Nordeste do Brasil. (Lauraceae). Rodriguésia 23/24(35): 241-251. 
Vattimo-Gil, I. 1966a. Lauraceae do Estado da Guanabara. Rodriguésia 25(37):75-113 .

Vattimo-Gil, I. 1966b. Notas sobre o gênero Cryptocarya R.Br. no Brasil (Lauraceae). Rodriguésia 25(37): 219-231.

Vattimo-Gil, I. 1976. Estudos sobre Ocotea Aubl., Phyllostemonodaphne Kosterm. e Licaria Aubl. (Lauraceae). Rodriguésia 28(41): 121-127.

Vattimo-Gil, I. 1979. Lauráceas. Pp. 55-92. In: R. Reitz (ed.). Flora Ilustrada Catarinensis. Itajaí, Herbário Barbosa Rodrigues.

Vaz, A.M.S.F. 1992. Diversidade de plantas vasculares na floresta atlântica do Rio de Janeiro. Boletim do Museu de Biologia Mello Leitão 1: 77-82.

Weber, J.Z. 1981. A taxonomic revision of Cassytha (Lauraceae) in Australia. Journal of the Adelaide Botanic Gardens 3: 187-262.
Werff, H. van der. 1984. Notes on Neotropical Lauraceae. Annals of the Missouri Botanical Garden 71: 1180-1183.

Werff, H. van der. 1987. A revision of Mezilaurus (Lauraceae). Annals of the Missouri Botanical Garden 74: 153-182.

Werff, H. van der. 1991. A key to the genera of Lauraceae in the New World. Annals of the Missouri Botanical Garden 78(2): 377-387.

Werff, H. van der. 1993. A revision of the genus Pleurothyrium (Lauraceae) Annals of the Missouri Botanical Garden 80: 39-118.

Werff, H. van der. 1994. Novelties in Neotropical Lauraceae. Novon 4: 58-76.

Werff, H. van der \& Richter, H.G. 1996. Toward an improved classification of Lauraceae. Annals of the Missouri Botanical Garden 83: 409-418. 